\title{
Ethical Considerations for the Participation of Children of Minor Parents in Clinical Trials
}

\author{
Mary A. Ott ${ }^{1}$ (1) Francis P. Crawley ${ }^{2}$ (1) $\cdot$ Xavier Sáez-Llorens $^{3,4} \cdot$ Seth Owusu-Agyei $^{5,6}$ • \\ David Neubauer $^{7}$ (D) Gary Dubin $^{8} \cdot$ Tatjana Poplazarova9 $^{\text {(D) }} \cdot$ Norman Begg $^{9,10}{ }_{(D)} \cdot$ \\ Susan L. Rosenthal ${ }^{11,12}$
}

Published online: 23 February 2018

(C) The Author(s) 2018. This article is published with open access at Springerlink.com

\begin{abstract}
Children of minor parents are under-represented in clinical trials. This is largely because of the ethical, legal, and regulatory complexities in the enrolment, consent, and appropriate access of children of minor parents to clinical research. Using a case-based approach, we examine appropriate access of children of minor parents in an international vaccine trial. We first consider the scientific justification for inclusion of children of minor parents in a vaccine trial. Laws and regulations governing consent generally do not address the issue of minor parents. In their absence, local community and cultural contexts may influence consent processes. Rights of the minor parent include dignity in their role as a parent and respect for their decision-making capacity in that role. Rights of the child include the right to have decisions made in their best
\end{abstract}

This article is part of the topical collection on Ethics of Pediatric Drug Research.

Mary A. Ott

maott@iu.edu

1 Division of Adolescent Medicine, Department of Pediatrics, Indiana University School of Medicine and Department of Philosophy, IUPUI (adjunct), 410 West 10th Street, HS 1001, Indianapolis, IN 46202, USA

2 Good Clinical Practice Alliance-Europe (GCPA), Brussels, Belgium

3 Pediatrics, Head of Infectious Diseases and Director of Clinical Research at Hospital del Niño Dr José Renán Esquivel, Panama City, Panama

4 Distinguished Investigator of the SNI (Senacyt) and Member of the National Ethics Committee in Biomedical Research, Panama City, Panama

5 Present Address: Epidemiology, Institute of Health Research, University of Health and Allied Sciences, Ho, Ghana interest and the right to the highest attainable standard of health. Children of minor parents may have vulnerabilities related to the age of their parent, such as increased rates of poverty, that have implications for consent. Neuroscience research suggests that, by age 12-14 years, minors have adult-level capacity to make research decisions in situations with low emotion and low distraction. We conclude with a set of recommendations based on these findings to facilitate appropriate access and equity related to the participation of children of minor parents in clinical research.

6 Kintampo Health Research Centre, Ghana Health Service, Ministry of Health, Kintampo, Ghana

7 Department of Pediatrics, Medical Faculty and University Medical Centre Ljubljana, University of Ljubljana, Bohoričeva 20, Ljubljana, Slovenia

8 Takeda Pharmaceuticals, Glattpark-Opfikon, Zurich, Switzerland

9 GSK Vaccines, Avenue Fleming 20, Parc de la Noire Epine, B-1300 Wavre, Belgium

10 Present Address: Norman Begg Consulting, Tervuren, Belgium

11 Medical Psychology (in Pediatrics and Psychiatry), Columbia University Medical Center-College of Physicians and Surgeons, New York, NY, USA

12 New York-Presbyterian Morgan Stanley Children's Hospital, New York, NY, USA 


\section{Key Points}

Excluding the children of minor parents from clinical trials raises issues of appropriate access and equity.

Minor parents should be involved in making decisions on research consent for their children.

There are circumstances in which consent of an additional adult may be appropriate.

\section{Introduction}

Current approaches to pediatric research focus on "appropriate access," recognizing the tension between protecting children from potential harms, and providing access to benefits $[1,2]$. For individual children, these include access to new treatments, and, for children as a group, expanding our knowledge of childhood disease, effective treatments, and improved health outcomes. The European Union's Clinical Trials Directive states that “... medicinal products which are likely to be of significant clinical value for children are fully studied. The clinical trials required for this purpose should be carried out under conditions affording the best possible protection for the subjects" [1]. Appropriate access has been framed as an issue of health equity [3].

Children of minor parents are a group that raises particularly complex ethical questions. These children are often under-represented, and there is little guidance regarding their enrolment in clinical trials. Children overall are considered a vulnerable population; children of minor parents may have additional vulnerabilities stemming from the age, developmental status, and socioeconomic conditions of their minor parents. The participation of children of minor parents in clinical research raises two important ethical questions: (1) should this potentially more vulnerable group of children participate in research, and (2) if so, who should consent to their participation?

This manuscript provides a review and discussion of the ethical considerations for the participation of children of minor parents in clinical trials. Using a case-based approach, we first consider the scientific justification for inclusion of children of minor parents, legal issues related to inclusion, and the community and cultural contexts. We then discuss appropriate access and equity, the balance between the rights of the minor parent and the rights of the child, the vulnerability of the child, and decision-making capacity of the minor parent. We provide a set of points to consider for appropriate access of children of minor parents to clinical research.

\section{Case Description and Approach: The COMPAS Study}

The COMPAS (Clinical Otitis Media and Pneumonia Study) was a phase III randomized double-blind controlled clinical trial of a pneumococcal conjugate vaccine conducted among 24,000 infants living in Panama, Argentina, and Colombia [4]. Although currently standard of care [5], pneumococcal conjugate vaccines were still in development at the time of the trial initiation in 2007. The COMPAS protocol, in accordance with international guidance [6], required that informed consent for children be obtained according to local law and be approved by the local ethics committee. However, the relevant local laws were not straightforward, and no specific law or guidance specified what to do when the consenting parent was a minor.

At the start of COMPAS in Panama, the ethics committee permitted minor parents to give research consent for their children, as for consent for children of adult parents. During the study, as part of a routine review, the local ethics committee changed its policy and asked that an adult (aged 18 years or older) provide an additional consent, beyond that of the minor parent. This additional adult could be the other parent (if over 18 years) or a grandparent. The minor parent was asked to re-consent alone for the child when the minor parent reached 18 years.

Post-trial analyses showed that COMPAS under-enrolled children of minor parents. In Panama, of 65,000 live births annually, approximately $20 \%$ are to mothers aged under 18 years, of which $80 \%$ are in the age group 16-17 years [7]. Despite this high proportion of minor parents in Panama, of approximately 7200 infant participants in COMPAS in Panama, only 211 children (3\%) had a minor parent provide consent, raising the question of whether children of minor parents had appropriate trial access.

In response to the ethical challenges faced by investigators conducting COMPAS, an international panel of volunteer experts (pediatrics and adolescent medicine, clinical trials, psychology, ethics, industry, medical governance) reviewed relevant literature and ethics guidelines to come to a consensus. We limited discussion to minor parents aged 14-17 years because, in most countries, 18 years is the age of legal adulthood, and minor parents aged 12-13 years represent a tiny but distinct group with respect to cognition, development, and legal status [8].

\section{Scientific Justification}

International guidance requires that the inclusion of children in clinical research be justified scientifically [9]. Worldwide, pneumonia accounts for $15 \%$ of deaths in children aged under 5 years [10], making it an important 
World Health Organization (WHO) target [11]. Children in poverty are disproportionately represented in pneumonia deaths because they have an increased risk of exposure to, and severity of, pneumococcal disease [12]. This risk is attributable to poor nutrition, less access to medical care, indoor air pollution from biomass fuels, overcrowding, and (potentially) immune response difference in children living in conditions of poverty [12].

The inclusion of children of minor parents in the COMPAS study was supported by the potential preventive effect of a pneumococcal vaccine. Compared with children of adult parents, children of minor parents experience higher rates of negative child health outcomes and higher rates of infant mortality from diseases such as pneumonia [13-17]. Because of these disparities, the children of minor parents constitute an important target population for pneumococcal vaccines.

When children of minor parents comprise a large and distinct group within a population, exclusion might result in scientific bias. This is a concern with phase III and IV trials, which are intended to provide a broad population basis regarding the safety and efficacy of an intervention. This is particularly relevant in parts of sub-Saharan Africa, where the proportion of women aged 15-19 years giving birth is $30-50 \%$, or in many Latin American and Caribbean countries, where it is $10-25 \%$ [18]. In the case of COMPAS, a more equitable inclusion of children of minor parents might have strengthened the generalizability of the trial.

\section{Legal Issues Related to Minor Parent Consent}

Informed consent is a voluntary decision to take part in research after being informed of the nature, significance, implications, and risks of the research, by a person legally capable of giving consent [1]. Assent is an affirmative agreement to participate in research after being informed about research procedures, risks, and benefits [19]. Assent is obtained when an individual has some degree of capacity to understand the research and make decisions, but does not have the legal authority to provide informed consent. For research with children, parents typically provide informed consent and children (over about 7 years of age) provide assent. This process is less clear when the parent is a minor.

Guidance for research with children requires that consent procedures follow local laws [6, 20], yet few countries have laws specific to consent from parents who are themselves minors. When there are no laws on research consent, research often follows laws for medical consent. Laws regarding medical decision-making authority and consent for children vary among and within countries [21]. Some countries clearly define the legal medical decision maker for the child of a minor parent. This authority might be given to the minor parent, to an adult family member (e.g., grandparent), or the other parent (if not a minor). Minor parents who are the heads of households and minors who are married may additionally be considered to have medical decision-making authority for their child. However, it is unclear how medical decision-making authority translates into research decision-making authority.

In the absence of laws governing medical consent for children of minor parents, there are differences based upon traditions, culture, or common practices. In some places, such as the USA, minor parents are assumed to have the same rights with respect to medical decisions for their child as adult parents. In contrast, in Panama and in most African settings, the child's grandparents or a head of household frequently make decisions.

While not directly applicable to the children of minor parents, laws regarding minors' medical consent for themselves may provide insight as to whether minors are generally given the right to consent, and indirectly, whether minors are believed to have the capacity to consent. Research ethics guidelines consider as children those who have not reached legal adulthood in their country (usually 18 years of age) (see, for example, The Council for International Organizations of Medical Sciences [CIOMS] [6] and US FDA regulations [22]). In many countries, minors aged under 18 years may consent for their own medical care in specific circumstances [23], and minors who may consent to clinical care are generally allowed to consent to research on the topic (e.g., HIV prevention [24]). For example, UK law defines a minor as being aged under 16 years for medical treatment and research, although the typical legal age of adulthood is 18 years. In the UK, the test of "Gillick competence" provides a legal basis for minors aged under 16 years to provide their own consent as long as they demonstrate the ability to understand the procedures involved and the consequences [25]. Recent UK research guidelines suggest that "Gillick competence" could also be applied to clinical research [25]. In the countries of the COMPAS study, the legal age of adulthood is 18 years, although children may be considered emancipated from their parents at 16 years in Panama and at 13-16 years in other Latin American countries [26].

In the COMPAS trial, the lack of specific laws for research or medical consent for children of minor parents created uncertainty and likely acted as an additional barrier to participation. When laws are unclear, investigators, sponsors, and ethics review committees must draw on ethical considerations in specifying consent approaches.

\section{Community Practices and Norms}

The Declaration of Helsinki recognizes the ethical importance of respecting local laws and practices [9]. Benchmarks for international research include ensuring community 
engagement and seeking community permission [6]. For example, in malaria clinical trials in Ghana and Mali, there were detailed community studies, engagement meetings, and ultimately community permission. These practices facilitated the process of individual informed consent [27, 28]. The rationale for changes in the consent process for the COMPAS trial was to achieve greater consistency with community norms in which the grandparent frequently assumes responsibility for the child of the minor parent.

\section{The Rights of the Minor Parent and the Rights of the Child}

Investigators, sponsors, and ethics committees need to balance the emerging capacity of adolescents for autonomous decision making with the need for special protections due to their minor status [29]. With regard to minor parents, this encompasses respect for the minor parent's role in decision making for their child.

Rights of parents stem from multiple sources, including local laws, community practices, and ethical justifications [30]. Conceptually, parental rights have been linked to the responsibilities and duties of the parent toward the child [30]. Parents are responsible for the welfare and healthy development of the child and have the right to make decisions for their child regarding topics such as diet, schooling, religion, and healthcare. Laws regarding parental authority generally do not specify a lower age limit. Minor parents are thus generally afforded the same legal rights as adult parents, including the right to make healthcare decisions for their child. Ethical justifications for parental rights include the assumption that parents generally make decisions in the best interest of the child. Assuming that the minor parents are fulfilling their responsibilities for caring for the child, we should recognize minor parents' rights to make decisions.

Children of minor parents also have rights. The Convention on the Rights of the Child asserts the primary importance of the child's right to have decisions made in their best interest (Article 3, paragraph 1) and goes on to affirm the child's right to the highest attainable standard of health (Article 24, paragraphs 1 and 4) [31]. Parental decision-making rights are necessarily limited by these rights of the child. Parental rights also might be limited by law (e.g., child abuse laws), incapacity of the parent, and cultural practices and norms [30, 31].

\section{Vulnerability}

One ethical question raised by COMPAS and other pediatric clinical trials is whether the children of minor parents have additional vulnerabilities related to research participation in comparison with children of adult parents. The Declaration of Helsinki defines vulnerability as "an increased likelihood of being wronged or of incurring additional harm" [9]. We consider vulnerability to be a set of characteristics and/or situations that may make an individual more likely to be wronged or experience harm [32]. Children are considered a vulnerable population in research and in need of additional protections. Child research participants may be vulnerable in multiple ways; for example, they may lack decisional capacity or be deferential to authority; they may be subject to the legal authority of others; and/or they may be socioeconomically disadvantaged, or otherwise belong to a group whose rights and interests are undervalued by society [33].

Special protections for children are codified in most human subject research guidance, such as CIOMS and the US Code of Federal Regulations (CFR 50) [6, 22]. For children, international guidance documents require additional justification for their inclusion. For example, the Declaration of Helsinki states that research with vulnerable populations is only justified "if the research is responsive to the health needs and priorities of this population or community and if there is a reasonable likelihood that this population or community stands to benefit from the results of the research [9]." The COMPAS trial tested a vaccine for pneumococcus, and pneumonia is a common cause of death that disproportionately affects children in high poverty settings [34]. Thus, children of minor parents stood to benefit from the trial. For a study to recruit from a vulnerable group, the specific type and degree of vulnerability, the risks of the research protocol, and the protections that can be put in place should all be considered [35].

Children of minor parents may have additional vulnerabilities related to the age of their parent, and these additional vulnerabilities have implications for research consent. Compared with children of adult parents, children of minor parents are more likely to live in poverty with its attendant risks, including less access to healthcare, lower education of their parents, and a greater power differential between the minor parent and the researcher [13-17]. Children of minor parents may be the product of child marriage [13-15, 35], with its increased risk of intrapersonal violence and coercion, making it possible that a married minor parent may not be able to make a voluntary, non-coercive decision on behalf of their child [36].

\section{Adolescent Decision-Making Capacity}

When that parent is herself (or himself) a minor, it raises the question of whether the minor parent has the capacity to provide permission. While a large body of data exists on adult capacity to consent to research [37], there is almost none on minor parents' capacity to consent to research for their child. 
During adolescence, individuals develop decision-making skills relevant to research, including the ability to understand complex and abstract concepts, attend selectively to information, accurately perceive risk, consider multiple conflicting viewpoints, and logically weigh risks and benefits [38-41]. Data from high-income countries suggest that, by age 12-14 years, adolescents have similar capacity to adults with regard to providing informed consent, including adequate understanding, reasoning, and evidence of choice [42-44]. Studies of adolescents' clinical trial decision-making capacity demonstrated that an adolescent's understanding of research concepts, such as randomization, placebo, and experimental design is generally similar to that described for adults [45-47].

Adolescent decision making differs from that of adults in two key areas relevant to research consent. The first is decision-making experience. Healthcare decision-making competence is related, in part, to one's experience making these decisions. Compared with adults, most minors have less healthcare decision-making experience. Assuming medical decision making improves medical research decision making, minor parents who are actively making medical decisions for their child will have more decisionmaking experience than minors in general.

Second, while adolescents make decisions similar to those of adults in situations that allow for logical, unhurried reasoning, adolescents frequently have more difficulty than adults in situations with high emotion or distraction [38, 41]. In COMPAS, participants were consented in settings with minimal distraction and with efforts taken to ensure that participants understood and made an autonomous choice. Therefore, it is reasonable to assume that, in such situations, the capacity of minor parents to make research decisions for their child is similar to that of adults. Additional decision supports may be needed for the safe participation of children of minor parents in higher risk or more complex research or when consent must be obtained in sub-optimal situations (e.g., research in emergency settings or with very sick children).

\section{Appropriate Access and Equity}

While pediatric guidance supports the inclusion of children, the experience with COMPAS suggests that, for clinical trials recruiting children of minor parents, investigators, sponsors, and ethics committees may need to consider not only the rights and welfare of the individual child for inclusion in clinical trials but also the need to ensure health equity (see Fig. 1). A health equity perspective focuses on fair and proportionate representation for vulnerable groups. A focus on appropriate access and health equity represents the ongoing shift in paradigms surrounding research with children: from research viewed primarily from the perspective of its potential risks to research viewed from a more balanced perspective that includes its potential benefits.

Research guidelines (e.g., CIOMS and Declaration of Helsinki) encourage the appropriate access, rather than the exclusion, of populations under-represented in research $[6,9]$. Compared with adults, children in general are underrepresented in clinical trials, and regulatory guidance increasingly encourages inclusion with additional attention to safety, rather than exclusion (see, for example, Gill [48] and US National Institutes of Health [49]). The COMPAS experience suggests that children of minor parents may have even less access to clinical trials. Ethical and regulatory guidance (for example, the FDA's 21 CFR 50 [22] and European Medicines Agency guidance on pediatric clinical trials [50]) requires a consideration of trial risks, direct trial benefits, and the balance of these risks and benefits. This type of risk-benefit assessment favors inclusion in trials such as COMPAS, in which the risks and benefits are well understood based on previous pediatric trials or adult studies. In the COMPAS study, children of minor parents stood to benefit to the same extent as children of adult parents.

Well-designed clinical trials may also provide benefits beyond the direct benefits of the intervention or medication. In many low-resource settings in which neither the resources nor the health infrastructure are available to provide universal access to high-quality general pediatric care, research participation gives both the child and their minor parent access to research personnel, medical personnel, and health facilities. This indirect benefit raises ethical concerns: the lack of access to care creates vulnerability because research decisions might be made not on the risk-benefit assessment of the intervention but rather on the basis of enhanced access to medical care [35]. This is a particular concern for children of minor parents because of their higher rates of poverty. Investigators, sponsors, and ethics committees need to acknowledge and manage this potential vulnerability [51].

\section{Discussion and Points to Consider}

Our review of ethical guidance and data on decisionmaking capacity suggests that children of minor parents ought to be included in clinical research when it concerns health issues relevant to them, with the following points warranting consideration:

1. While international research documents advise investigators and sponsors to follow local law with respect to minor parent consent, if local law is silent, vague, or 
Fig. 1 Key ethical issues for children of minor parents
Key Ethical Issues for Children of Minor Parents

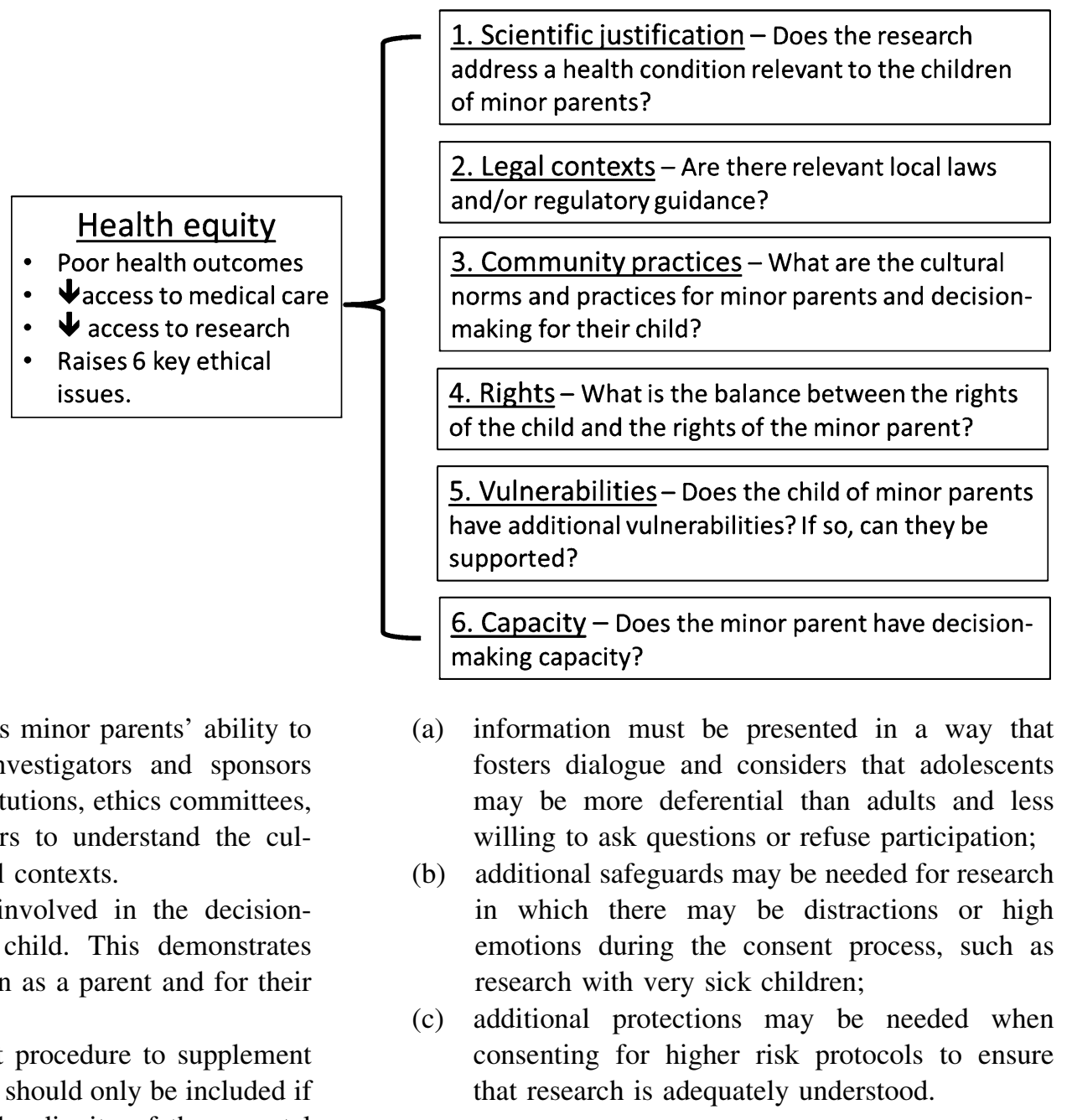

5. The design and execution of the consent process and research procedures should support or mitigate any vulnerabilities that are more typically seen in children of minor parents. These might include those stemming from the minor parents' developmental status, decision-making capacity, literacy level, poverty, legal rights, and cultural contexts.

6. Investigators, sponsors, and ethics review committees should consider community engagement processes to better understand the roles, rights, and responsibilities of the minor parent with respect to their child, taking into consideration prevailing social, cultural, and traditional contexts.

Sponsors, investigators, and ethics committees have a responsibility to carefully consider the access of children of minor parents to clinical trials and ensure, as appropriate, opportunities to participate in research. Government regulatory agencies should also consider addressing this 
pediatric population when developing guidance for clinical trials.

Acknowledgements This analysis was previously presented as a poster at the Pediatric Academic Societies (PAS) Annual Meeting, May 06-09, 2017, San Francisco, CA, USA. Editorial services were provided by Mary Greenacre (independent medical writer, Isle of Barra, Scotland, UK) and funded by GlaxoSmithKline Biologicals SA. Editing and publication coordinating services were provided by Véronique Delpire and Mandy Payne (Words \& Science, Brussels, Belgium) and funded by GlaxoSmithKline Biologicals SA.

Contributors' Statements Prof. Ott contributed to the development of the ideas and arguments, conceptualized the case report format, drafted and revised the initial manuscript, and approved the final manuscript. Prof. Sáez-Llorens was the site principal investigator on the COMPAS trial, contributed to the development of the ideas and arguments (in particular, provided expertise on minor consent in the COMPAS study and pediatric trials in Latin American contexts), critically reviewed drafts of the manuscript, and approved the final manuscript. Prof. Owusu-Agyei contributed to the development of the ideas and arguments (in particular, provided expertise on minor consent for pediatric trials conducted in Africa and high poverty contexts), critically reviewed drafts of the manuscript, and approved the final manuscript. Mr. Crawley, Prof. Neubauer, Dr. Dubin, and Ms. Poplazarova contributed to the development of the ideas and arguments, critically reviewed drafts of the manuscript, and approved the final manuscript. Prof. Rosenthal contributed to the development of the ideas and arguments, provided oversight on manuscript development, critically reviewed drafts of the manuscript, and approved the final manuscript. All authors approved the final manuscript as submitted and agree to be accountable for all aspects of the work.

Funding All costs related to the development of this manuscript were met by GlaxoSmithKline Biologicals SA, including editorial and coordination support and reimbursement of airfare, hotel, and meal expenses associated with attendance of the panel meeting at the GSK site in Wavre, Belgium. Francis P. Crawley neither asked for nor received any reimbursement. Costs related to open access publication were met by GlaxoSmithKline Biologicals SA.

\section{Compliance with Ethical Standards}

Conflict of interest Mary Ott's spouse is an employee of Eli Lilly, Inc., and the couple are small stockholders in Eli Lilly, Inc. Gary Dubin is currently employed by Takeda Pharmaceuticals but was employed by the GSK group of companies for most of the period of manuscript development; he currently owns stocks in the GSK group of companies and was a co-inventor on a number of patents in the herpes simplex virus (HSV) and human papilloma virus (HPV) vaccine field. Tatjana Poplazarova is an employee of the GSK group of companies and holds shares in the GSK group of companies as part of her employee remuneration. Norman Begg was employed by the GSK group of companies at the time of manuscript development. He holds shares in, and acts as a consultant to, the GSK group of companies. Francis Crawley, Xavier Sáez-Llorens, Seth Owusu-Agyei, David Neubauer, and Susan Rosenthal have no conflicts of interest that are directly relevant to this article.

Open Access This article is distributed under the terms of the Creative Commons Attribution-NonCommercial 4.0 International License (http://creativecommons.org/licenses/by-nc/4.0/), which permits any noncommercial use, distribution, and reproduction in any medium, provided you give appropriate credit to the original author(s) and the source, provide a link to the Creative Commons license, and indicate if changes were made.

\section{References}

1. European Parliament and Council. Directive 2001/20/EC of the European Parliament and of the Council (Clinical Trials Directive). European Commission. 2011. http://ec.europa.eu/health/ files/eudralex/vol-1/dir_2001_20/dir_2001_20_en.pdf. Accessed 1 Aug 2015.

2. National Commission for the Protection of Human Subjects of Biomedical and Behavioral Research. Research involving children: recommendations of the National Commission for the Protection of Human Subjects of Biomedical and Behavioral Research. Washington, D.C.: U.S. GPO; 1977.

3. Bavdekar SB. Pediatric clinical trials. Perspect Clin Res. 2013;4(1):89-99.

4. Tregnaghi MW, Saez-Llorens X, Lopez P, Abate H, Smith E, Posleman A, et al. Efficacy of pneumococcal nontypable Haemophilus influenzae protein D conjugate vaccine (PHiD-CV) in young Latin American children: a double-blind randomized controlled trial. PLoS Med. 2014;11(6):e1001657.

5. World Health Organization. Pneumococcal vaccines, WHO position paper-2012. Wkly Epidemiol Rec. 2012; 87(14):129-44.

6. Council for International Organizations of Medical Sciences (CIOMS). International Ethical Guidelines for Health-related Research Involving Humans, Fourth Edition. Geneva, 2016. https://cioms.ch/wp-content/uploads/2017/01/WEB-CIOMSEthicalGuidelines.pdf. Accessed 5 Dec 2017.

7. Gobierno de la Republica de Panama. Estudios especializados del Censo de Poblacion y Vivienda de 2010. In: Atlas Social. 2011. http://www.mef.gob.pa/es/informes/Paginas/Atlas-Social.aspx. Accessed Nov 2015.

8. Child Trends Databank. Fertility and birth rates. 2015. http:// www.childtrends.org/?indicators=fertility-and-birth-rates. Accessed 26 Aug 2015.

9. World Medical Association. Declaration of Helsinki: ethical principles for medical research involving human subjects. In: Amended by the 52nd WMA General Assembly, Edinburgh, Scotland, 2000 and Clarified by the WMA General Assembly, Washington, 2002 and Tokyo, 2004. 2004.

10. World Health Organization. Pneumonia. Fact sheet No 331. 2014. http://www.who.int/mediacentre/factsheets/fs331/en/. Accessed 26 Aug 2015.

11. World Health Organization. Causes of Child Mortality. 2015. http://www.who.int/gho/child_health/mortality/causes/en/. Accessed 1 Oct 2015.

12. Wardlaw T, Johansson EW, Hodge M. Pneumonia: The Forgotten Killer of Children. New York, NY: The United Nations Children's Fund (UNICEF)/World Health Organization (WHO) 2006 Contract No.: ISBN-13: 978-92-806-4048-9.

13. Taffa N. A comparison of pregnancy and child health outcomes between teenage and adult mothers in the slums of Nairobi, Kenya. Int J Adoles Med Health. 2003;15(4):321-9.

14. Jutte DP, Roos NP, Brownell MD, Briggs G, MacWilliam L, Roos LL. The ripples of adolescent motherhood: social, educational, and medical outcomes for children of teen and prior teen mothers. Acad Pediatrics. 2010;10(5):293-301.

15. Fleming N, Ng N, Osborne C, Biederman S, Yasseen AS 3rd, Dy $\mathrm{J}$, et al. Adolescent pregnancy outcomes in the province of Ontario: a cohort study. J Obstet Gynaecol Can JOGC. 2013;35(3):234-45. 
16. World Health Organization. Adolescent pregnancy. 2018. Available from: http://www.who.int/mediacentre/factsheets/ fs364/en/. Accessed 17 Jan 2018.

17. Mollborn S, Lawrence E, James-Hawkins L, Fomby P. How resource dynamics explain accumulating developmental and health disparities for teen parents' children. Demography. 2014;51(4):1199-224.

18. US Agency for International Development. Demographic and Health Surveys (DHS) Program STATcompiler. 2014. http:// www.statcompiler.com/. Accessed Dec 2014.

19. US Department of Health \& Human Services. 45 CFR 46, Subpart D. Protection of Human Subjects, Additional Protections for Children Involved as Subjects in Research. Code of Federal Regulations. 2005.

20. Gill D, Crawley FP, LoGiudice M, Grosek S, Kurz R, de Lourdes-Levy M, et al. Guidelines for informed consent in biomedical research involving paediatric populations as research participants. Eur J Pediatr. 2003;162(7-8):455-8.

21. Alderson P. Competent children? Minors' consent to health care treatment and research. Soc Sci Med. 2007;65(11):2272-83.

22. US Food and Drug Administration (FDA). 21 CFR 50, Protection of Human Subjects, Subpart D. Code of Federal Regulations. Available at: https://www.accessdata.fda.gov/scripts/cdrh/cfdocs/ cfcfr/CFRSearch.cfm?CFRPart $=50 \&$ showFR $=1 \&$ subpartNode $=$ 21:1.0.1.1.20.4. Accessed 28 Nov 2017.

23. Guttmacher. An Overview of Minors' Consent Law. State Policies in Brief. 21 August 2014.

24. Nelson RM, Lewis LL, Struble K, Wood SF. Ethical and regulatory considerations for the inclusion of adolescents in HIV biomedical prevention research. J Acquir Immune Defic Syndr. 2010;54(Suppl 1):S18-24.

25. Modi N, Vohra J, Preston J, Elliott C, Van't Hoff W, Coad J, et al. Guidance on clinical research involving infants, children and young people: an update for researchers and research ethics committees. Arch Dis Child. 2014;99(10):887-91.

26. UNICEF Regional Office for Latin America and the Caribbean. Adolescents in Latin America and the Caribbean: policy guidelines. Bogotá: The United Nations Children's Fund (UNICEF); 2001.

27. Asante KP, Agyemang CT, Zandoh C, Saah J, Febir LG, Donlebo $\mathrm{CK}$, et al. Community engagement in biomedical research in an African setting: the Kintampo Health Research Centre experience. BMC Health Serv Res. 2013;13:383.

28. Diallo DA, Doumbo OK, Plowe CV, Wellems TE, Emanuel EJ, Hurst SA. Community permission for medical research in developing countries. Clin Infect Dis. 2005;41(2):255-9.

29. Santelli JS, Smith Rogers A, Rosenfeld WD, DuRant RH, Dubler $\mathrm{N}$, Morreale M, et al. Guidelines for adolescent health research. A position paper of the Society for Adolescent Medicine. J Adolesc Health. 2003;33(5):396-409.

30. Brake E, Millum J. Parenthood and Procreation. In: The Stanford Encyclopedia of Philosophy. 2014. http://plato.stanford.edu/ archives/fall2014/entries/parenthood/. Accessed 1 Oct 2015.

31. Convention on the Rights of the Child, General Assembly resolution 44/25. 1990.

32. Iltis AS. Vulnerability in biomedical research. J Law Med Ethics. 2009;37(1):6-11.

33. Kipnis K. Seven vulnerabilities in the pediatric research subject. Theor Med Bioeth. 2003;24(2):107-20.

34. UN Inter-agency Group for Child Mortality Estimation. Levels \& trends in child mortality: Report 2015. New York: United Nations Children's Fund; 2015.

35. Grady C. Vulnerability in research: individuals with limited financial and/or social resources. $J$ Law Med Ethics. 2009;37(1):19-27.
36. Raj A. When the mother is a child: the impact of child marriage on the health and human rights of girls. Arch Dis Child. 2010;95(11):931-5.

37. Appelbaum PS. Consent in impaired populations. Curr Neurol Neurosci Rep. 2010;10(5):367-73.

38. Blakemore SJ, Robbins TW. Decision-making in the adolescent brain. Nat Neurosci. 2012;15(9):1184-91.

39. Reyna VF, Rivers SE. Current theories of risk and rational decision making. Dev Rev. 2008;28(1):1-11.

40. Waber DP, De Moor C, Forbes PW, Almli CR, Botteron KN, Leonard G, et al. The NIH MRI study of normal brain development: performance of a population based sample of healthy children aged 6 to 18 years on a neuropsychological battery. J Int Neuropsychol Soc. 2007;13(5):729-46.

41. Steinberg L. Does recent research on adolescent brain development inform the mature minor doctrine? J Med Philos. 2013;38(3):256-67.

42. Hein IM, De Vries MC, Troost PW, Meynen G, Van Goudoever $\mathrm{JB}$, Lindauer RJ. Informed consent instead of assent is appropriate in children from the age of twelve: policy implications of new findings on children's competence to consent to clinical research. BMC Med Ethics. 2015;16(1):76.

43. Weithorn L, Campbell S. The competency of children and adolescents to make informed treatment decisions. Child Dev. 1982;53(6):1589-98.

44. Nelson LR, Stupiansky NW, Ott MA. The influence of age, health literacy, and affluence on adolescents' capacity to consent to research. J Empir Res Hum Res Ethics JERHRE. 2016;11(2):115-21.

45. Ott MA, Alexander AB, Lally M, Steever JB, Zimet GD, The Adolescent Trials Network for HIV/AIDS Interventions. Preventive misconception and adolescents' knowledge about HIV vaccine trials. J Med Ethics. 2013;39:765-71.

46. Hill Z, Tawiah-Agyemang C, Odei-Danso S, Kirkwood B. Informed consent in Ghana: what do participants really understand? J Med Ethics. 2008;34(1):48-53.

47. Blake DR, Lemay CA, Kearney MH, Mazor KM. Adolescents' understanding of research concepts: a focus group study. Arch Pediatr Adolesc Med. 2011;165(6):533-9.

48. Gill D, Ethics Working Group of the Confederation of European Specialists in Paediatrics. Ethical principles and operational guidelines for good clinical practice in paediatric research. Recommendations of the Ethics Working Group of the Confederation of European Specialists in Paediatrics (CESP). Eur J Pediatr. 2004;163(2):53-7.

49. National Institutes of Health. Children and Clinical Studies: Why Do Research in Children? 2012. http://www.nhlbi.nih.gov/ childrenandclinicalstudies/whydo.php. Accessed 26 Jan 2013.

50. Ethical considerations for clinical trials on medicinal products conducted with minors: Recommendations of the expert group on clinical trials for the implementation of Regulation (EU) No $536 / 2014$ on clinical trials on medicinal products for human use. Revision 1, 18 September 2017. European Commission. 2017. https://ec.europa.eu/health/sites/health/files/files/eudralex/vol-10/ 2017_09_18_ethical_consid_ct_with_minors.pdf. Accessed 5 Dec 2017.

51. Ravinetto RM, Afolabi MO, Okebe J, Van Nuil JI, Lutumba P, Mavoko HM, et al. Participation in medical research as a resource-seeking strategy in socio-economically vulnerable communities: call for research and action. Trop Med Int Health TM IH. 2015;20(1):63-6. 